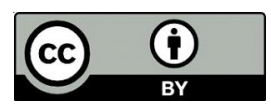

Submitted: 07.03.2021 Accepted: 05.04.2021

\title{
THE PROSECUTOR AS A COORDINATOR OF THE LAW ENFORCEMENT ACTIVITIES IN THE FIGHT AGAINST CRIME
}

\author{
Anatoly P. Kruglikov \\ Volgograd State University, Volgograd, Russian Federation
}

Introduction: the paper analyzes some problems of coordinating the activities of the law enforcement agencies in the fight against crime, and the role of the prosecutor in this activity. The author notes that the achievement of significant positive results in the fight against crime is only possible with a clear coordination of the actions of the law enforcement agencies carried out in accordance with the law. These bodies are named in the Regulation on the coordination of the activities of law enforcement agencies in the fight against crime approved by Presidential Decree No. 567 of April 18, 1996, with the subsequent amendments by other Decrees of the President of the Russian Federation, the latest of which is Decree No. 640 of December 31,2019. Such bodies are: the bodies of internal affairs of the Russian Federation, bodies of the Federal Security Service, troops of the National Guard of the Russian Federation, bodies of the criminal executive system of the Russian Federation, bodies of compulsory enforcement of the Russian Federation, customs bodies of the Russian Federation, investigative bodies of the Investigative Committee of the Russian Federation and some other bodies. In accordance with Part 1 of Article 8 of the Federal Law "On the Prosecutor's Office of the Russian Federation", the activities of the law enforcement agencies to combat crime are coordinated by the Prosecutor General of the Russian Federation, the prosecutors of the subjects of the Russian Federation, cities, districts and other territorial prosecutors, as well as military and other specialized prosecutors equated to them. In accordance with the above-mentioned Provision, the objectives of coordination are to increase the efficiency of fight against crime by developing and implementing coordinated measures by these bodies for the timely detection, solving, suppression and prevention of crimes, eliminating the causes and conditions that contribute to their commission. When writing the work, various methods of scientific knowledge were used: systematicity, analysis, synthesis, the formal-legal one, etc. Results: the author considers the basic principles of coordination of the activities of the law enforcement agencies, its main directions and forms. Conclusions: the practice of coordinating the activities of the law enforcement agencies should be constantly analyzed to study the best practices in the prevention and detection of crimes, the protection of the rights and freedoms of citizens in criminal proceedings, and to take into account the essence of court decisions made based on the results of the reviewed activities.

Key words: coordinator, coordination activity, principles and forms of coordination activity, the role of the prosecutor as a coordinator of the investigated activity.

Citation. Kruglikov A.P. The Prosecutor as a Coordinator of the Law Enforcement Activities in the Fight Against Crime. Legal Concept = Pravovaya paradigma, 2021, vol. 20, no. 2, pp. 21-25. (in Russian). DOI: https:// doi.org/10.15688/lc.jvolsu.2021.2.3

УДК 343.163

Дата поступления статьи: 07.03.2021

ББК 67.72

Дата принятия статьи: 05.04.2021

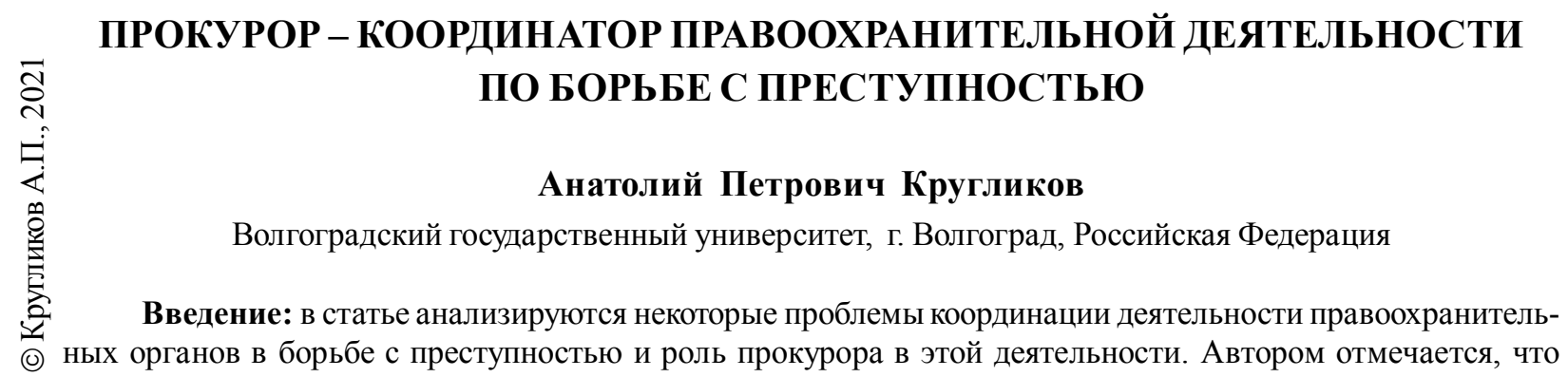


достижение значимых положительных результатов в борьбе с преступностью возможно лишь при четкой, осуществляемой в соответствии с законом, координации действий правоохранительных органов. Эти органы названы в утвержденном Указом Президента Российской Федерации от 18 апреля 1996 г. № 567 Положении о координации деятельности правоохранительных органов по борьбе с преступностью - с последующими изменениями другими Указами Президента РФ, последним из которых был Указ от 31.12.2019 № 640. Такими органами являются: органы внутренних дел Российской Федерации, органы федеральной службы безопасности, войск национальной гвардии Российской Федерации, органы уголовно-исполнительной системы Российской Федерации, органы принудительного исполнения Российской Федерации, таможенные органы Российской Федерации, следственные органы Следственного комитета Российской Федерации и некоторые другие. В соответствии с ч. 1 ст. 8 Федерального закона «О прокуратуре Российской Федерации» деятельность правоохранительных органов по борьбе с преступностью координируют Генеральный прокурор Российской Федерации, прокуроры субъектов Российской Федерации, городов, районов и другие территориальные прокуроры, а также приравненные к ним военные и иные специализированные прокуроры. В соответствии с названным Положением целями координации являются повышение эффективности борьбы с преступностью путем разработки и реализации указанными органами согласованных мер по своевременному выявлению, раскрытию, пресечению и предупреждению преступлений, устранению причин и условий, способствующих их совершению. При написании работы использованы различные методы научного познания: системности, анализа, синтеза, формально-юридический и др. Результаты: автором рассмотрены основные принципы координации деятельности правоохранительных органов, ее главные направления и формы. Выводы: практика координации деятельности правоохранительных органов должна постоянно анализироваться для изучения передового опыта в предупреждении и раскрываемости преступлений, охраны прав и свобод граждан в уголовном судопроизводстве, для учета сущности судебных решений, принимаемых по результатам рассмотренной деятельности.

Ключевые слова: координатор, координационная деятельность, принципы и формы координационной деятельности, роль прокурора в качестве координатора исследуемой деятельности.

Цитирование. Кругликов А. П. Прокурор - координатор правоохранительной деятельности по борьбе с преступностью // Legal Concept = Правовая парадигма. - 2021. - T. 20, № 2. - C. 21-25. - DOI: https://doi.org/ 10.15688/lc.jvolsu.2021.2.3

\section{Введение}

Координатор - это лицо, осуществляющее координацию чего-либо [3]. «“Координация - согласование”, а “координировать”значит согласовывать» [4]. Координацию правоохранительной деятельности в России осуществляет прокурор. Эта его функция закреплена в указанных нормативных актах, служащих основой ее осуществления.

В целях обеспечения координации деятельности правоохранительных органов прокуроры созывают координационные совещания. В состав координационного совещания входят прокурор (председатель совещания) и руководители соответствующих правоохранительных органов или исполняющие их обязанности (члены совещания). Совещание созывается председателем по мере необходимости, но не реже одного раза в квартал, а также по инициативе одного из членов координационного совещания. Члены координационного совещания при обсуждении вопросов пользуются равными пра- вами. Решение координационного совещания оформляется в письменной форме в виде постановления и считается принятым, если оно одобрено руководителями правоохранительных органов, на которых возлагается его выполнение. Руководители правоохранительных органов во исполнение решений координационного совещания издают приказы, указания, распоряжения и принимают соответствующие организационно-распорядительные меры. Если в реализации решения участвует несколько правоохранительных органов, организационное обеспечение возлагается на орган, указанный в решении первым. Члены координационного совещания при обсуждении вопросов пользуются равными правами.

Председатели судов, руководители органов юстиции могут принимать участие в координационных совещаниях правоохранительных органов, с учетом высказанных ими пожеланий по приглашению председателя совещания.

Координация деятельности правоохранительных органов осуществляется на основе 
принципов, закрепленных в Положении:законности. Участники совместной деятельности должны знать, что нарушение прав и свобод граждан, других важнейших положений уголовно-процессуального законодательства неизбежно повлечет утрату полученных доказательств; равенства всех участников координационной деятельности при постановке вопросов, внесении предложений, разработке рекомендаций и мероприятий. Это гарантирует проявление инициативы при обсуждении и принятии тех или иных решений; самостоятельности каждого правоохранительного органа в пределах предоставленных ему законодательством Российской Федерации полномочий при выполнении согласованных решений, рекомендаций и проведении мероприятий; гласности в той мере, в какой она не противоречит требованиям законодательства Российской Федерации о защите прав и свобод человека и гражданина, о государственной и иной охраняемой законом тайне; ответственности руководителя каждого правоохранительного органа за выполнение согласованных решений.

Координация обеспечивает слаженное и целенаправленное взаимодействие правоохранительных органов, устраняет межведомственные препятствия и дублирование в их деятельности.

Выступая на расширенном заседании коллегии в Генеральной прокуратуре РФ 19 марта 2019 г. Президент Российской Федерации В.В. Путин, в частности, отметил: «Одним из приоритетных направлений работы прокуратуры остается координация действий правоохранительных органов в борьбе с преступностью. Важно совершенствовать механизмы взаимодействия с МВД, Следственным комитетом и другими ведомствами для снижения уровня криминала, экстремизма, коррупции, настаивать на строгом соблюдении закона при приеме, регистрации и рассмотрении сообщений о преступлениях, а также при оформлении и передаче статистической информации. Необходимо своевременно выявлять и устранять нарушения в работе органов, занимающихся оперативно-розыскной деятельностью, а также осуществлять надзор за качеством расследования уголовных дел, причем на всех этапах следствия» [2].

\section{Основные направления и формы координационной деятельности}

Они названы в Положении, все они очень значимы, из них остановимся лишь на двух - подготовке обзоров состояния координационной деятельности и планах ее осуществления.

В повышении эффективности координационной деятельности важную роль играют обзоры состояния координационной деятельности территориальных и специиализированных прокуратур, ежегодно составляемые прокуратурами субъектов Российской Федерации.

В них отражается совместный анализ состояния преступности, ее структуры и динамики, прогнозируются тенденции практики выявления, расследования, раскрытия, предупреждения и пресечения преступлений. На основе обобщения практики применения законов по борьбе с преступлениями вырабатываются конкретные предложения по улучшению правоохранительной деятельности, высказываются рекомендации по совершенствованию правового регулирования деятельности по борьбе с преступностью, предлагаются различные мероприятия, исходя в том числе из состояния преступности в конкретном регионе.

Обзоры дают четкое представление о координационной деятельности в определенный период времени в конкретном субъекте Российской Федерации, о плюсах и минусах данной деятельности. Например, в обзоре за первое полугодие 2019 г. отмечено, что прокурорами в Волгоградской области проведено значительное количество координационных совещаний руководителей правоохранительных органов всех уровней, на которых рассмотрены многие вопросы, связанные с борьбой с преступностью. 25 таких мероприятий были посвящены противодействию коррупционным преступлениям. Из обзора видно, что в результате проделанной работы удалось достигнуть определенных успехов в борьбе с преступностью, активизировать работу правоохранительных органов по выявлению наркопреступлений и проявлений организованной преступности, повысить уровень раскрываемости отдельных категорий уголовно-наказуемых деяний. Вместе с тем говорится в об- 
зоре, что принимаемых мер в борьбе с преступностью недостаточно и что некоторыми прокурорами допущены существенные нарушения при планировании и реализации координационной функции, отрицательно сказавшиеся на ее результативности [1].

Из обзора состояния координационной деятельности территориальных и специализированных прокуратур в Волгоградской области за 2020 г. видно, что за отмеченный период органами прокуратуры региона проведено много координационных совещаний. 35 из них были посвящены противодействию коррупционным проявлениям. Помимо координационных и межведомственных совещаний в указанном году использовались иные формы координационной деятельности в виде совместных проверок (35), семинаров (50) и выездов (11), издания совместных организационно-распорядительных и информационно-методических документов (8). По отдельным направлениям деятельности создано 235 межведомственных рабочих групп, результатом функционирования которых в анализируемом периоде явилось проведение 410 совещаний.

В рассматриваемом году многими прокурорами были запланированы и проведены координационные мероприятия, посвященные вопросам противодействия хищениям с использованием информационно-коммуникационных технологий, что обусловлено возросшей криминальной активностью в данной сфере правоотношений. По их результатам выработаны и реализуются механизмы борьбы с подобными противоправными посягательствами.

К примеру, прокурором Н-ского района данный вопрос обсужден в сентябре 2020 г. в формате координационного совещания, в ходе которого внимание руководителей территориальных правоохранительных органов обращено на необходимость использования имеющихся методических материалов по выявлению указанных преступлений и их расследованию. Указана необходимость своевременной дачи поручений оперативным подразделениям для установления информации о владельцах абонентских номеров и банковских счетов, на которые перечислены денежные средства потерпевших.
Каждое уголовное дело такой категории взято на особый контроль в прокуратуре района, с промежуточными докладами о ходе следствия на оперативных совещаниях. Принятые координационные меры способствовали повышению уровня раскрываемости краж, совершенных с банковских счетов граждан.

Кроме положительных результатов, выявлены в указанный период и недостатки в координационной деятельности. В ряде районов отмечены случаи, когда в соответствующих планах не указываются сроки реализации мероприятий, выработанных по итогам координационных совещаний, это препятствует надлежащему контролю за их исполнением и оценке эффективности названных мероприятий. На подобные упущения обращалось внимание в информационно-аналитических документах, направляемых прокуратурой региона, однако необходимые меры для их искоренения не были приняты [1].

Качественной, эффективной и законной координационной деятельности способствует ее надлежащее планирование. Положением ему отведена важная роль. Прокуроры и руководители правоохранительных органов при планировании координационной деятельности в качестве ориентира на 2020 г. руководствовались «Планом основных мероприятий по координации деятельности по борьбе с преступностью правоохранительных органов Российской Федерации на 2020 год», подписанным Председателем Координационного совещания Генеральным прокурором Российской Федерации.

Планом предусматривался, например, анализ деятельности правоохранительных органов по выявлению, пресечению и расследованию преступлений, связанных с незаконной миграцией. Результаты предполагалось обсудить на межведомственном совещании в первом квартале 2020 года.

Руководители правоохранительных органов субъектов Российской Федерации составляют свои планы, в которых учитывается специфика определенного региона, в том числе характер и распространенность определенных преступлений, практика их расследования, допускаемые ошибки в правоохранительной деятельности, положительный опыт такой деятельности. 
Так, в плане основных мероприятий по координации деятельности правоохранительных органов Волгоградской области по борьбе с преступностью на 2019 г. предусматривалось обсудить состояние законности при объявлении правоохранительными органами в розыск и осуществление розыска лиц, скрывшихся от органов предварительного расследования, а также выполнить ряд других действий. Результаты выполнения должны были рассмотреть на межведомственных совещаниях [1].

\section{Выводы}

Исследование показало руководящую роль прокурора в координации правоохранительной деятельности, выявило положительный опыт и недостатки при ее осуществлении, значение для закрепленных в Конституции РФ охраны прав, свобод и законных интересов граждан.

\section{СПИСОК ЛИТЕРАТУРЫ}

1. Архив прокуратуры Волгоградской области за 2019 год.

2. Прокурор. -2019 . - № 1. - С. 6.

3. Словарь иностранных слов. - 19-е изд., стер. - М. : Рус. яз., 1990. - 259 c.

4. Словарь синонимов русского языка / под ред. Л. А. Чешко. - Изд. 4-е, репродуц. - М. : Рус. яз., $1975 .-200 \mathrm{c}$.

\section{REFERENCES}

1. Arkhiv prokuratury Volgogradskoy oblasti za 2019 god [Archive of the Prosecutor's Office of the Volgograd Region for 2019].

2. Prokuror [Prosecutor], 2019, no. 1, p. 6.

3. Slovar inostrannykh slov [Dictionary of Foreign Words]. $19^{\text {th }}$ ed., ster. Moscow, Russian Language, $1990.259 \mathrm{p}$.

4. Cheshko L.A., ed. Slovar sinonimov russkogo yazyka [Dictionary of Synonyms of the Russian Language]. Ed. $4^{\text {th }}$, reproduced. Moscow, Russian Language, $1975.200 \mathrm{p}$.

\section{Information About the Author}

Anatoly P. Kruglikov, Candidate of Sciences (Jurisprudence), Professor, Department of Criminal Procedure and Criminalistics, Honorary Worker of Higher Professional Education of the Russian Federation, Volgograd State University, Prosp. Universitetsky, 100, 400062 Volgograd, Russian Federation, kruglikov@volsu.ru,https://orcid.org/0000-0001-8656-3688

\section{Информация об авторе}

Анатолий Петрович Кругликов, кандидат юридических наук, профессор, профессор кафедры уголовного процесса и криминалистики, почетный работник высшего профессионального образования РФ, Волгоградский государственный университет, просп. Университетский, 100, 400062 г. Волгоград, Российская Федерация, kruglikov@volsu.ru, https://orcid.org/0000-0001-8656-3688 